\section{Basic Oral Radiology}

Author(s)/Editor(s): Anil Govindrao Ghom

Publisher: Jaypee Brothers Medical Publishers (P) Ltd

Language: English

ISBN: 978-93-5152-321-5

Edition: $1 / \mathrm{e}$

Publish Year: 2014

Pages: 208, illustrated

Price: $\$ 45.60$

DOI: https://doi.org/10.25241/stomaeduj.2016.3(3-4).bookreview.4

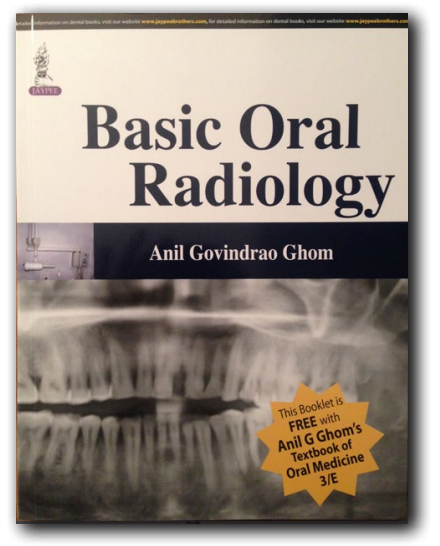

Professor Anil Govindrao Ghom published this textbook in order to facilitate the understanding of basic diagnostic oral radiology. This book has nineteen chapters and starts with a brief overview of the history of radiology. The next two chapters describe the physical principles of the radiology and x-ray machines. Throughout the book, the author refers to radiation biology and protection, as well as the projection of the geometry base in the processing of X-ray films. It is to be noted that the book approaches a subject like infection control which is not considered in practice. Intraoral and extraoral radiographic techniques, specialized intraoral techniques and normal anatomical landmarks are presented in the following chapters. TMJ and salivary gland imaging are referred to in separate chapters. References to the principles of radiographic interpretation and undiagnostic radiography are clarified. This textbook achieves its purpose and is an excellent guide that helps students, doctors and teachers to acquire the fundamentals of oral radiology.

The Books Review is drafted in the reviewer's sole wording and illustrates his opinions. 